\title{
Professional Learning in Unlikely Spaces: Social Media and Virtual Communities as Professional Development
}

\author{
http://dx.doi.org/10.3991/ijet.v6i4.1765 \\ K.P. King \\ University of South Florida, Tampa, FL USA
}

\begin{abstract}
In this case study, results demonstrate that an individual's use of social media as professional learning spans understanding, networking, professional identity development, and transformative learning. Specifically, virtual online communities facilitated through social media provide professional networks, social relationships and learning beyond the scope of the individual's usual experience. Case study method reveals strategies, extent, and impact of learning providing insight into this phenomenon. The significance of the research includes purposefully facilitating professional learning through informal learning contexts, including social media and online communities beyond technologycentric fields. Discussion and recommendations include using social media and virtual communities as instructional strategies for graduate studies and continued learning beyond formal education.
\end{abstract}

Index Terms - Transformative learning, social media, informal learning, professional development, learning communities

\section{INTRODUCTION}

Building upon the robust literature of learning communities $[1 ; 2 ; 3]$, this case study explores online and virtual spaces as professional development and transformative learning communities. Specifically, the research examines the experience of a graduate student engaged in informal learning through online (primarily based in Twitter and blogs) communities as she experienced transformative learning [4]. The study reveals that the virtual community greatly advanced her professional learning, preparation, understanding and appreciation of a specific mental health diagnosis and related treatments.

The mental health context of professional learning has been legitimately conducted online $[5 ; 6]$ for several years, providing a valuable context of learning and research [7] in examining transformative learning through online communities spaces. Discussions with colleagues led to this research project in which the study analyzed the student's postings, journal entries, and recorded her journey's account for specific evidence of transformative learning $[4 ; 8]$. Moreover, the analysis explored how these experiences provide direction for the use of virtual communities as meaningful professional development.

\section{THEORETICAL BACKGROUND}

Three foundational areas provide a broad, interdisciplinary theoretical background for this research study and discussion: transformative learning, distance learning, and cybercultures. Frequently, research and literature of professional development of teachers and faculty in formal settings have examined these experiences from a transformative learning (TL) perspective $[9 ; 10 ; 11 ; 12 ; 13$; 14]. These studies reveal that, in supportive and safe environments, TL opportunities may emerge from professional development $[13 ; 15 ; 16]$. Moreover, building upon these studies, new perspectives of teaching gained through TL impact professionals and their practice $[16 ; 17]$. In another line of research, several recent studies identify how faculty [18] and students [19] experience TL through online courses in various roles as adult learners. Together, this background research demonstrates the potential for meaningful TL professional development within varied learning contexts, which this present study extends to virtual, informal learning.

The literature on distance learning demonstrates how to construct and facilitate meaningful learning communities online $[20 ; 21]$. At the same time, these and other authors recognize that the essential and familiar principles and practices of socially constructed knowledge [22], social discourse in learning, and situated learning [1] are at the core of these virtual learning relationships. Rather than isolated, silo learning experiences in virtual space, this foundation emphasizes the dynamic collaboration and dialogue inherent to life-changing online professional development. Certainly, this perspective belies the common fear of technology as an isolating force in our society, instead celebrating the role of online relationships and community.

A related body of literature from the fields of sociology, philosophy, and information sciences, research and literature on "cyberculture," has been growing in since the 1970 s $[23 ; 24 ; 25]$. This literature tracks scholarly efforts to frame the changes and tends between and among traditional relationships and dialogue and those conducted through technology and/or solely online. In addition, it tracks the rapid development of technology, online communities and social adoption during this time [26]. In 2005-2007, an enormous public adoption of social media ensued: not only was the general public using online resources for accessing information, but also social media to communicate with colleagues, friends and relatives (i.e., Facebook, Twitter, MySpace, Friendster, etc.), to strengthen networks (i.e., LinkedIn, Ning, Tumblr, etc.) and as illustrated in this study, extend their learning communities [26].

This present research study extends prior work on formal distance learning and cyberculture to informal learn- 
ing contexts, revealing new opportunities for building beneficial global virtual professional learning environments. The results provide several informative insights about the nature and possibilities for professional development in virtual communities. For instance, such learning does not need to be a focused effort of every participant, but may be as simple as self-directed, professional and academic curiosity through virtual dialogue with a group of like-minded people. Professional learning in these contexts requires the individuals to pursue it with a high level of motivation and focus.

\section{RESEARCH Method AND DATA COLLECTION}

It is widely accepted that a valid use of the case study method is to examine new phenomenon [27;28]. The merit of case study for such research is its ability to provide direction for more specific future analysis. In this research study, case study is the methodology and frame; however, while some case studies may be narrowly focused, this study uses several strategies to collect a wide variety of data forms. This section describes the method and rationale for the research and analysis, as well as providing details regarding participants.

\section{A. Method}

In Stake's schema [29], this case study research is an intrinsic case study, as the researcher has a stake in the study. It is also a single case (rather than multiple cases) application. The design incorporates several forms of data collection, thus providing greater validity through triangulation [28; 29]. Additionally, Denzin's [30] model of triangulation specifies the methodological triangulation of this study: researchers gathered data in different ways from the same participants, and about the same experience.

Specifically, this study gathered and analyzed several different forms of data, which, according to Yin [28] have varied strengths as well as weaknesses. For instance, documentation such as the primary participant's journal entries, transcripts of twitter logs of the community, and instant message/chat between the participant and some community members all have a high degree of accuracy and stability but may be difficult to retrieve and be overly broad and unfocused [28], p. 86. In fact, social media overcomes much of the retrieval difficulty. To counterbalance the potential lack of focus of data limitation, the design includes an interview with the main subject of the study, "Patty."

Qualitative analysis consisted of constant comparison until exhaustion (saturation) of discovery and identification of themes [31]. In addition, data display, chronological flow charts, pattern-matching and explanation-building were used to chart several activities occurring during the case, and the common behaviors identified among and within them [28].

As per Yin's [28] framework, the original research design addressed issues of validity and reliability in the following manner. Multiple sources of evidence and member-checking of the draft case study report ensured construct validity, thereby countering claims of researcher subjectivity. Pattern-matching and explanation-building sustained internal validity, theoretical frame of transformative learning contributed to external validity, and the use of a case study protocol- interview questions and data gathering and analysis procedures ensured reliability.

\section{B. Participants}

The primary participant in this study is a woman, "Patty." In 2008, she completed her BA in psychology in her 40 's. The next semester she began her MSW at a research university, focusing on mental health therapy. Prior to the financial crisis of 2008, Patty was an accomplished business professional; therefore, it is not surprising that she applied professional practices of focus and dedication to her studies. For example, she pursued additional reading, career related volunteer opportunities, and association memberships to advance her career during and in between semesters. To continue to learn more about her new career, Patty began reading several blogs (websites, which frequently have new content and characteristically invite comments from readers) about a specific acute mental health disorder.

The other participants in the study were involved indirectly. These contributors were Patty's virtual informal learning community members. She met these people interested in discussing this specific mental health disorder through topic-related public blogs and began following them in those blogs and on Twitter. Gradually, frequent correspondence progressed among a group who had informally gathered around a common mental health topic.

One curious and powerful element of this group is that some of the virtual community participants were licensed professionals, others (like Patty) were unlicensed but interested in the topic, and several were not in mental health-related careers but had the mental health condition. This study examines Patty's professional learning experience in this dynamic, informal virtual community, and she was the only participant directly contacted for this research study.

Patty agreed to participate in this study on one condition: that the study would not reveal the identity of her online community, because she did not want the study to compromise their effective support system. In order to accomplish this goal, in all written accounts the pseudonym "Patty" represents the main interviewee and the acute mental disorder she studied, nor the specific blogs, Twitter lists and identities, etc. she follows for this purpose remain anonymous to readers. In this manner, all participants and details remain anonymous in all publications related to this study.

\section{FINDINGS AND ANALYSIS}

The data revealed that Patty gained substantial learning and insight during the 14 months (2009-2011) she dialogued with this community. The descriptions of the discussions she relates and the available online archives provide insight into the depth and nature of this informal group's communication, relationships, and learning.

\section{A. Community Develops}

One insight, which surprises many people about this study is learning that people use not only public blogs, but also private blogs to share their ideas and views. This fact reveals the need to clearly identify the sequence of Patty's exploration or discovery of this specific virtual community.

Figure 1 illustrates how Patty progressively participates in public and the private blogs, followed participants on Twitter, and earned Facebook access for a few. In essence, she discovers the community through a series of steps and 


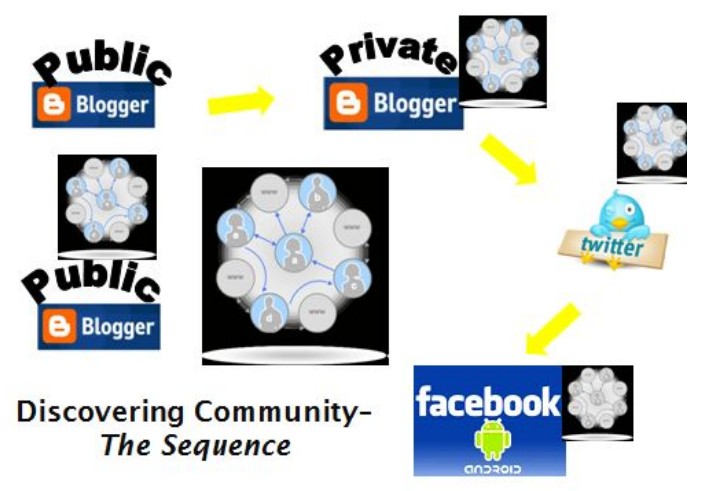

Figure 1. Discovering the Community Sequence

choices. Moreover, it illustrates that each locus of dialogue is a cluster or group, which did not necessarily continue to the next group. Patty's journey among her informal virtual communities is complex: it is open/not concentric and appears capable of growing/expanding.

\section{B. Professional Development Benefits}

Within these virtual spaces, some of the most profound examples of the continuing online conversations include important professional learning for Patty. Surprisingly, the ongoing and shifting conversations also demonstrate the ability to develop intimate sharing in a virtual space. Moreover, the impact of this continuing dialogue far exceeds that expected in formal educational settings [20].

Primary examples of the benefits drawn from the interviews and dialogue include (1) when participants with the mental health condition initiated online discussions with Patty about their experiences, thereby serving as invaluable primary sources for learning about their conditions, (2) when she learned more about the personal experience of this condition from them through discussions about their daily lives, treatments, and conflicts, (3) when Patty actively examined professional ethical boundaries within this new context (beyond the scope of her studies and prior preparation), and (4) when cross-cultural understandings were built and sustained through relatively freely flowing dialogue with people from many different cultures. Several illustrations of these benefits emerge over the months. One Saturday afternoon, Patty serves as a supportive friend through IM and Skype when someone is in a moderate crisis. Patty relates another instance where, for several weeks, the group continued to learn foreign colloquial terms and cultural differences from a few "group" members in another country. Patty also describes understanding the complexity of living daily with the disorder in a "completely new light" because of the on-going private blogs that some participants post for them to read.

A valuable means of organizing these findings emerged in the analysis process. Patty's professional development (PD) benefits from this informal virtual community fit in two groups. Table 1 displays these analysis results. The results revealed 10 discrete examples labeled with the theme "benefits," as well as two composite "developments" of greater professional understanding.

Regarding Professional Skill Development, these characteristics will help Patty succeed as a mental health therapist. The experience of situated learning experience (learning in action and in context [1]) provides a vibrant opportunity for praxis, often missing from formal education such as professional graduate schools.
TABLE I.

PD BENEFITS OF INFORMAL VIRTUAL COMMUNITY

\begin{tabular}{|c|c|c|}
\hline & Benefits & Composite \\
\hline 1. & $\begin{array}{l}\text { Expanding scope of social network } \\
\text { diversity beyond the customary social } \\
\text { network to a virtual network }\end{array}$ & \multirow{6}{*}{$\begin{array}{l}\text { Essential Addi- } \\
\text { tional Skills } \\
\text { Development }\end{array}$} \\
\hline 2. & $\begin{array}{l}\text { Developing cross-cultural understanding as } \\
\text { she dialogued with people from many } \\
\text { different cultures }\end{array}$ & \\
\hline 3. & $\begin{array}{l}\text { Learning from personal accounts of people } \\
\text { with severe mental health conditions }\end{array}$ & \\
\hline 4. & $\begin{array}{l}\text { Developing dialogue practice and strategies } \\
\text { to be supportive of people with mental } \\
\text { health conditions }\end{array}$ & \\
\hline 5. & $\begin{array}{l}\text { Developing reflective practice techniques } \\
\text { to comprehend needs }\end{array}$ & \\
\hline 6. & $\begin{array}{l}\text { Developing reflective practice techniques } \\
\text { to develop appropriate responses }\end{array}$ & \\
\hline 7. & $\begin{array}{l}\text { Developing additional skills in etiquette, } \\
\text { cautions, and difficulties in written } \\
\text { communication regarding delicate and } \\
\text { emotion-laden topics. }\end{array}$ & \multirow{4}{*}{$\begin{array}{l}\text { Professional } \\
\text { Identity Devel- } \\
\text { opment }\end{array}$} \\
\hline 8. & $\begin{array}{l}\text { Building appreciation for and sense of } \\
\text { boundaries in mental health support roles }\end{array}$ & \\
\hline 9. & $\begin{array}{l}\text { Appreciating many ethical quandaries } \\
\text { licensed practitioners encounter based on } \\
\text { accounts of participants (while not } \\
\text { disclosing opinions). }\end{array}$ & \\
\hline 10. & $\begin{array}{l}\text { Recognizing the extensive support licensed } \\
\text { practitioners must provide mental health } \\
\text { clients with acute diagnoses. }\end{array}$ & \\
\hline
\end{tabular}

The Essential Additional Skills Development dimension represents skills which added to her repertoire of professional knowledge and practice. For example, as her social network expanded through virtual spaces, she encountered a greater variety of people from different classes, cultures, professions, and with different mental health conditions. As she developed better communication skills across different cultures through this virtual community, she will be able to transfer these skills to other electronic and in-person communications.

As Patty describes the value of this construct, "It has opened a whole different door for a learning experience about something which is still needs to be better understood in the mental health field. It is fascinating because mental health conditions haves to do with brain function, which is different for these people. Their coping mechanisms work so differently than I could imagine. Actually hearing their stories and experiences firsthand helps me appreciate their lives with the condition and helps me understand it so much better than theory does."

She talked at length about the value of the relationships and dialogue in the informal community for learning about the mental health condition of interest. Specifically, Patty hears and reads first-hand accounts of life with the condition and interacts with these individuals.

The professional identity development is similar to that experienced through structured internships. The benefit here is that the virtual community provides opportunities which may exceed the variety or depth of experiences locally available. In addition, there is greater flexibility for involvement, as the learner can interact with the community members anytime, any place. 
There is a double dimension to Patty's professional learning. She learned (1) about the mental health condition and the people with it, and (2) how to support people in a nonclinical relationship. In the literature of transformative learning, the first example is defined as the theoretical framework of the domains of knowledge [15]

Using this paradigm, it is evident that Patty's learning also spanned communicative learning (how to support people) and emancipatory learning. Patty's greater understanding and appreciation for the life situations of people with this mental health condition was emancipatory, and may ultimately inform her professional practice.

When asked about how the informal learning experience will affect her as a professional, Patty replied, "I will be able to recognize symptoms of the condition much more easily. I also appreciate that I will continue to learn a lot from my clients, just as I have learned from the people in the community who have the condition.... I've also learned about the client-professional relationship from these folks. I have to be sensitive to things that I as a therapist might do which would irritate clients or the confound transference process. Things I would never have thought of and which I have not read about either.

I also heard many of them talk about how when they are quiet in therapy they want to be drawn out. I can't tell you how many times I read that they want to be drawn out, but the therapist just sits in silence for the whole hour. Then the clients leave and are so mad at themselves, because they wanted to talk and couldn't and ultimately did not get help in that session.

Another thing is at least clients with this condition are very sensitive to responsiveness of the therapist whether by phone or email. If they send a message and do not hear right back (24 hours) they get so upset, it becomes drama. If go days or a week until they hear, their anxieties ratchet up and it can create a rupture in therapy and their condition can get worse."

Not only has Patty's professional identity and perspective changed, but also Patty described a "profound" qualitative benefit. This profound experience resulted from the primary source nature of the experience. In this manner, an additional finding surfaced: her circle of relationships broadened. Despite not knowing anyone in person with these conditions, she built meaningful, virtual relationships with people who have the condition and learned about life with it directly from them, rather than secondhand accounts. In an idiosyncratic manner, mental health workers often have friends or family with specific conditions with which they then gain familiarity and knowledge. However, it is a population limited by variables such as genetics, class, race, geography, chance, and more, thereby not ensuring exposure to a specific condition of interest. Essentially, the virtual space provided a larger circle of different people for potential interactions and relationships. Furthermore, rather than engaging in idle talk, Patty used this opportunity to engage in selfdirected reflection and professional learning.

When the analysis applied the lens of transformative learning to examine the data, the TL stages and final perspective transformation emerged. For example, the TL model illuminates Patty's disorienting dilemma when she privately questioned her prior experience against what she read posted by this virtual group.
"The first time some of the mental health participants posted their concerns while experiencing their conditions, I thought they were joking around. Quickly though when the same conversations turned to serious matters of violence, I realized "OK, this is not what I thought it was. This behavior is part of the disease, not a joke."

As noted by Zaro, Barach, Nedelman, and Dreiblatt [32], experienced clinicians develop skills to recognize clients' shifts in communication. These shifts often surface among clients with such conditions as major depression, manic-depression, psychoses, schizophrenia, dissociative identify disorder, and other mental health disorders. However, the public, students, and beginning therapists are less adept with identifying the patterns and find them confusing, even frustrating. Based on this information, the fact that Patty continued to develop these clinical skills through a virtual community has great import for therapists in training.

\section{Transformative Learning Dimensions}

TL theory reveals still another stage in Patty's learning journey as she negotiated relationships in her learning. Specifically, she had to build professional and personal understanding among the participants through dialogue.

As Patty describes, "I was sure to let them know I was accepting of what they were going through. I didn't make a big deal of it, although I would ask questions and express concern. I took an approach of letting them tell me, letting them offer information, rather than probing. I was aware it was much slower than I would usually learn about someone. I felt it was more appropriate to wait for them to be ready to talk to me."

Indeed, the other community members' trust and confidence in Patty became evident when several members invited her to join their private, password-protected blogs (Figure 1). It was in these private online spaces that the members posted their more personal insights and struggles. Patty would post general public comments, which were supportive and encouraging. At times, she would also email or privately post a message of support to the author.

Over time, she learned that many of these same people also posted on Twitter and Facebook. As she followed them (befriended them online to see their public posts), the other members reciprocated by following her public Twitter posts. (It is curious to note that in this study, this community did not use Facebook as much as Twitter despite its public popularity).

The Twitter conversations tended to be less formal that blog postings. In addition, the Twitter posts were in several forms: (1) general public posts to anyone "listening/reading", (2) posts continuing conversations among their small group of people interested in this mental health condition, and (3) direct messages to individuals in the informal group.

Examining social media dialogue, such as the dialogue Patty experienced and its resulting virtual community, there are striking findings to parallel potential introductory/informal internship settings. For instance, Patty now recognizes that she used a positive psychology approach by focusing discussions on constructive rather than destructive issues [33]. The conversations often centered on mental health disease; therefore, it was important to develop trust and transparency through dialogue [32]. 


\section{DISCUSSION}

\section{A. Ethics}

Based on Patty's' account, it is essential to emphasize two framing findings from this study (1) Patty exercised great caution to interact in a non-clinical role (not as a mental health worker) in her communications, and (2) she greatly respected the privacy and concerns of the people who shared their lives with her. When queried about the connection, Patty verified that ethical conduct tenets are core guidelines for professional practice within her field and a dominant theme in her formal academic studies. Moreover, while she later did some literary research on the topic of online counseling, her instructors never discussed ethical practice and issues related to electronic or online relationships or communities.

This study revealed two major examples of Patty's ethical awareness and actions [34]. First is her insistence on identifying and responding as a student and friend and not offering any counseling. Second is her concern for the privacy of her virtual community members in this study. Patty smoothly and quickly transferred the contexts of learning about ethical practice to the online virtual spaces.

\section{B. Self-Directed}

Traditional, professional graduate education follows a pattern of teacher-directed, formal instruction. The successful approaches in this case study are self-directed, voluntary, and informal learning. Currently, the method of pursuing professional learning through social media runs contrary to the way that most people have been educated, much as the voluntary efforts suggested by Grell and Raau [35]. Therefore, many people might have to be convinced to use this approach. However, this interviewee reveals that self-directed learning is a successful means to keep pace with the constantly changing expansion of new knowledge today ([26;7]), and may be powerful when applied across lifelong professional development. A great challenge practitioners and educators face is how to help people stay current in their field. Perhaps social media will be a platform and strategy to advance learning far beyond the classroom.

\section{Context is Important}

Most people want to know what lies ahead; it gives them security. When the future is uncertain, such people do not eagerly seek change $([35 ; 14])$. Just considering the complexities and barriers of introducing change and innovation among organizations is substantial proof of this enduring aversion to risk.

However, the mental health field has seen some professionals adopting online technologies for conducting therapy with clients already. There are many psychology, social work, and psychiatry professional associations which offer continuing education units and voluntary professional development in e-learning, mobile and hybrid formats. Moreover, counselors and mental health therapists have been using online modes for providing client therapy for several years. Modes for such technology-assisted treatment include phone, secure environments for email (i.e., Hushmail.com), and virtual offices hosted via private synchronous discussion spaces or webcam [36].

Therefore, this professional community provides a receptive and ready context to accept and even seek professional learning within this setting [36]. Other professions, less welcoming towards online technologies, might not be as well-suited for this adoption, and this difference may hinder or require specific approaches to introduce professional learning through such media. The literature identifies strategies for assessing organizational readiness for social media, Harfoushi and Obiedat [37] being a recent example.

In their model of e-training acceptance factors, the three major "readiness factors" were system functionality, human capabilities and financial resources [37]. Within the context of informal learning environment and voluntary, individual learning, the same acceptance factors appear to have been satisfied in this study. Patty found free online tools which provided the means of communication she needed within her scope of independent learning. Effective further analysis could test the hypothesis in the future.

\section{RECOMMENDATIONS, FUTURE RESEARCH AND SIGNIFICANCE}

\section{A. Recommendations for Practice}

This study provides the opportunity to consider virtual and social media communities as viable internship or practice spaces for professionals in a host of fields. The transformative learning Patty experienced resulted in a profound change in her professional and personal awareness. Such ongoing professional learning could be indispensable for interns and experienced practitioners in providing situated rather than solely theoretical learning. By incorporating such communicative and emancipatory learning into professional development, there would also be greater opportunities for new insights, refreshment and persistence in a burnout-heavy field (mental health providers).

However, this study also illustrates that Patty exercised substantial degrees of compassion and ethical awareness. Incorporating these practices, identified as key themes in this case, is essential for successful professional learning through social media that upholds the ethical codes of the social sciences (i.e., APA, NASW, ACA). If faculty or organizations decide to encourage social media as professional learning, they need to be certain that these critical issues are explored and understood by "students" prior to embarking on activities. In addition to the immediate learning they will gain, students will have broad based benefits throughout their careers from learning appropriate and wise choices.

Finally, another application of this study is to consider how the incorporation of virtual communities into professional learning could affect formal and informal professional learning across different fields. If faculty introduced these strategies into graduate courses or faculty development, professionals could dialogue continuously with new and current colleagues rather than waiting for annual conferences and facing enduring isolation [38; 39].

Moreover, people equipped with this paradigm and practice of virtual learning communities could expand their learning network through first-hand contact with experts and colleagues within their specialty or additional areas. More than e-mail exchanges, this study reveals that a community of common interest and practice can develop in virtual spaces. Wenger [40] and others [20] have long researched and recognized the value of communities of practice in continuing professional growth. 
Additionally, social media and virtual learning communities provide an ever-expanding social network, which can provide practice in communication, empathy and appreciation of varied circumstances, and in this case's conditions, provide experience beyond customary family, friends and geographical boundaries.

\section{B. Future Research}

Building upon what is known about online communities and facilitating their development $[41 ; 42 ; 43]$, providing respectful environment [44], and building trust [15], this study opens the door for a new level of research and implementation for informal professional learning in virtual contexts. Several possibilities for research which stem from this study include examining: (1) the benefits and means of using virtual community discussion (or their transcripts) as an authentic context for understanding professional ethics; (2) greater breadth and variation of experiences in virtual professional learning among social service students, (3) outcomes and means for creating virtual simulations to incorporate such experiences in formal training, (4) whether there are similar professional learning benefits to this format among other occupations, (5) feasibility and means to support mental health learning and needs through greater global networks, and (6) continued work applying the Soft System Methodology (SSM) $[45 ; 46 ; 47]$ to informal learning much as Kurkela [48] did to formal learning in higher education.

\section{Significance}

Sometimes, educators search fruitlessly for meaningful ways to reveal real-life application to new students or novices. This research demonstrates that voluntary, informal virtual communities can be valuable vehicles for professional learning. The potential of blending social media technologies with informal and situated learning opens new dimensions of professional learning possibilities for many fields. Moreover, the potential of transformative learning experiences through self-direction could address vital needs for continuing professional refreshment, renewal and persistence.

\section{REFERENCES}

[1] J. Lave, and E. Wenger, Situated Learning. Cambridge, UK: Cambridge University Press, 1991.

[2] R, Palloff, and K. Pratt, Collaborating Online: Learning Together in Community. San Francisco: Jossey Bass, 2005.

[3] P. Senge, The Fifth Discipline. New York: Doubleday, 1994.

[4] J. Mezirow, and Associates, Fostering Critical Reflection in Adulthood. San Francisco: Jossey-Bass, 1990.

[5] International Society for Mental Health Society Online (ISMHSO). Home page. Retrieved from https://www.ismho.org/ 1997.

[6] R. Kraus, and J. Zack, Online counseling. New York: Elsevier, 2003.

[7] S. Merriam, R. Caffarella, and L. Baumgartner, Learning in Adulthood: A Comprehensive Guide. San Francisco: Jossey-Bass, 2006.

[8] E. O’Sullivan, Transformative learning. London: Zed Books, 1999.

[9] C. Whitelaw, M. Sears and K. Campbell, "Transformative learning in a faculty professional development context." Journal of Transformative Education, vol. 2 no. 1, pp. 9-27, 2004. http://dx.doi.org/10.1177/1541344603259314

[10] S. E. Brock, "Measuring the importance of precursor steps to transformative learning." Adult Education Quarterly vol 60 no. 2, pp. 122-142, 2010. http://dx.doi.org/10.1177/0741713609333084
[11] P. Cranton, Transformative Learning in Professional Development. San Francisco, Jossey-Bass, 1996.

[12] T. Irani, and R. Telg, "The University of Florida's distance education faculty training program." Paper presented to the Southern Association of Agricultural Scientists, Orlando, FL, 2002, unpublished.

[13] K. P. King, Keeping Pace with Technology: Educational Technology that Transforms Vol. 1. Cresskill, NJ: Hampton Press, 2002.

[14] K. P. Keeping Pace with Technology: Educational Technology that Transforms. Vol. 2: Faculty Development in Higher Education. Cresskill, NJ: Hampton Press, 2003.

[15] P. Cranton, Understanding and Promoting Transformative Learning: A Guide for Educators of Adults. San Francisco, CA: JosseyBass, 2006.

[16] A. Kitchenham, "Teachers and technology: A transformative journey." Journal of Transformative Education vol. 4 no.3, pp.202225, 2006. http://dx.doi.org/10.1177/1541344606290947

[17] P. Cranton, and K. P. King, "Transformational learning as a professional development goal." in New Perspectives on Designing and Implementing Professional Development for Teachers of Adults, New Directions in Adult and Continuing Education. K. P. King, and P. A. Lawler, Eds. San Francisco: Jossey-Bass, 2003, pp. 31-38.

[18] P. Lari, Understanding Teaching Experiences: Faculty Transitions From Traditional To Online Classrooms. North Carolina State University. Raleigh, NC. Doctoral dissertation, 2008.

[19] J. Wasnick, J. Transformative Learning in Online Learning. Oklahoma State University, Ada, OK. Doctoral dissertation. Proquest, UMI 3259579, 2007.

[20] R. Palloff, and K. Pratt, Lessons from the Cyberspace Classroom: The Realities of Online Teaching. San Francisco, CA: JosseyBass, 2001.

[21] S. Stewart, A Study of Instructional Strategies That Promote Synchronous Dialogue Online. University of South Florida, Tampa FL. Doctoral dissertation ProQuest, LLC. UMI No. 3347372, 2008.

[22] L. Vygotsky, Mind and Society. 1978. Retrieved from http://www.marxists.org/archive/vygotsky/works/mind/index.htm

[23] D. Bell, Cybercultures. New York: Routledge, 2006.

[24] P. Levy, Collective Intelligence: Mankind's Emerging World in Cyberspace. New York: Basic Books, 1999.

[25] P. Levy, Cyberculture. R. Bononno (Trans). Minneapolis: University of Minnesota Press, 2001.

[26] T. Bingham, and M. Conner, The New Social Learning: A Guide to Transforming Organizations Through Social Media. Alexandria, VA: ASTD, 2010.

[27] S. Merriam. Qualitative Research and Case Study Applications in Education (Rev.ed.). San Francisco: Jossey-Bass, 1997.

[28] R. K. Yin, Case Study Research (2nd ed.) Thousand Oaks, CA: Sage, 2009.

[29] R. Stake, The Art of Case Research. Newbury Park, CA: Sage Publications, 1995.

[30] N. Denzin, The Research Act. Englewood Cliffs, NJ: Prentice Hall, 1984.

[31] V. Janesick, V. Handbook of the Arts in Qualitative Inquiry. Thousand Oaks, CA: Sage, 2007.

[32] J. S. Zaro, R. Barach, D. J. Nedelman, and I. S. Dreiblatt, A Guide for Beginning Psycho-therapists. New York: Cambridge, 1997.

[33] P. A. Linley, and S. Joseph (Eds.), (2004). Positive Psychology in Practice. New York: Wiley, 2004.

[34] R. Brockett, and R. Heimestra, Toward Ethical Practice. Malabar, FL: Krieger Publishing Company, 2004.

[35] P. Grell, and F. Rau "Social participation under compulsion" International Journal of Emerging Technologies in Learning, vol 5 no. 4, July 2010. doi:10.39991/ijet.v5i4.1458

[36] M. Fullan, "The meaning of educational change: A quarter of a century of learning." in The Roots of Educational Change A. Gieberman, Ed. New York: Springer, 2005, pp. 202-216.

[37] O. Harfoushi and R. Obiedat, "E-Training acceptance factors in business organizations." International Journal of Emerging Tech- 
nologies in Learning, vol 6 no. 2, 2011. http://dx.doi.org/ 10.39991/ijet.v6i2.1443

[38] International Society for Mental Health Society Online (IMHSO). Home page. Retrieved from https://www.ismho.org/ 1997.

[39] R. Caffarella, Planning Programs for Adult Learners (2nd ed.). San Francisco: Jossey-Bass, 2002.

[40] P. A. Lawler, and K. P. Effective Faculty Development: Using Adult Learning Principles. Malabar, FL: Krieger, 2000.

[41] Wenger, E. Communities of Practice. Cambridge: Cambridge University Press, 1999.

[42] Cranton, P. Teaching for transformation. New Directions for Adult and Continuing Education, 93, 2002, pp. 63-72. http://dx.doi.org/10.1002/ace.50

[43] P. Senge, The Fifth Discipline. New York, NY: Doubleday, 1994.

[44] A.Ramli, I. Ismail, and R. Izdrus. "Mobile learning via sms among distance learning: does learning transfer occur?" International Journal of Interactive Mobile Technologies, vol 4 no. 3, July 2010. http://dx.doi.org/10.39991/ijim.v4i3.1180

[45] R. Palloff, and K. Pratt, The Virtual Student. A Profile and Guide to Working with Online Learners. San Francisco, CA: Jossey Bass, 2003.

[46] P. Checkland, and S. Holwell, Information, Systems and Information Systems: Making Sense of the Field. John Wiley \& Sons, 1998.
[47] P. Checkland, and J. Scholes, Soft Systems Methodology in Action. John Wiley \& Sons, 1999.

[48] P. Checkland, Systems Thinking, Systems Practice. John Wiley \& Sons, 1999.

[49] L. Kurkela, "Systematic Approach to Learning Paradigms and the Use of Social Media in Higher Education." International Journal of Emerging Technologies in Learning, vol 6 no. 1, July 2011. http://dx.doi.org/10.39991/ijim.v6S1.1616

\section{AUTHOR}

K. P. King is with the University of South Florida, Tampa, FL 33647 USA (e-mail: KathleenKing@ USF.edu).

Dr. Kathleen P. King is a professor of higher education at USF, Tampa FL. She is an award-winning auth and has published 20 books and 175+ articles and papers. Kathy's research and publishing areas include e-learning, social media, diversity, adult and higher education, leadership and faculty development.

Received 27 July 2011. Published as resubmitted by the author 22 November 2011. 